\title{
Growth of upper tropospheric aerosols due to uptake of $\mathrm{HNO}_{3}$
}

\author{
S. Romakkaniemi ${ }^{1}$, H. Kokkola ${ }^{1}$, A. Petzold ${ }^{2}$, and A. Laaksonen ${ }^{1}$ \\ ${ }^{1}$ University of Kuopio, Department of Applied Physics, Kuopio, Finland \\ ${ }^{2}$ Deutsches Zentrum für Luft und Raumfahrt Oberpfaffenhofen, Institut für Physik der Atmosphäre, Wessling, Germany
}

Received: 24 October 2003 - Published in Atmos. Chem. Phys. Discuss.: 7 January 2004

Revised: 1 March 2004 - Accepted: 24 March 2004 - Published: 30 March 2004

\begin{abstract}
The effect of nitric acid on the equilibrium size distributions of upper tropospheric aerosols is calculated as a function of relative humidity. It is shown that $\mathrm{HNO}_{3}$ concentrations above a few tenths of a ppb can cause substantial increases in haze mode particle concentrations at relative humidities at about $60 \%$ and above. The effect can be strongly magnified when letovicite particles are present in addition to sulfuric acid aerosols. Letovicite particles are less acidic than the sulfuric acid particles and so more nitric acid can be absorbed. This effect can be seen even at RH below $50 \%$ due to the lowering of the deliquescence $\mathrm{RH}$ of letovicite in the presence of gaseous nitric acid at low temperatures. We have also compared equilibrium calculations of the $\mathrm{HNO}_{3}$ effect with observations of increased haze mode concentrations at relative humidities above 50\% (Petzold et al., 2000). Nitric acid mixing ratios on the order of $0.5-2$ ppb may explain the observed increase of haze mode particles at least partially.
\end{abstract}

\section{Introduction}

Aerosols in the upper troposphere and stratosphere are mainly composed of $\mathrm{H}_{2} \mathrm{SO}_{4}$ and $\mathrm{H}_{2} \mathrm{O}$ but also ammoniated sulfate and other components have been observed (Xu et al., 2001; Sheridan et al., 1994; Murphy et al., 1998). It has been shown that binary $\mathrm{H}_{2} \mathrm{SO}_{4} / \mathrm{H}_{2} \mathrm{O}$ aerosols can effectively take up $\mathrm{HNO}_{3}$ and turn into supercooled ternary solutions before freezing homogeneously (Tabazadeh et al., 1994; Kärcher and Solomon, 1999). Uptake of $\mathrm{HNO}_{3}$ increases the hygroscopic mass of aerosols, causing further growth of the droplets due to absorption of water. This affects both the optical properties of the aerosols and the stratospheric heterophase chemistry.

Correspondence to: S. Romakkaniemi

(sami.romakkaniemi@uku.fi)
Recently, Petzold et al. (2000) made observations about the occurrence of haze-mode aerosols in the upper troposphere. The number of haze mode particles increased abruptly as the saturation ratio exceeded 0.5 . It was argued that the particles were likely to be composed of ammoniated sulfates undergoing deliquescence transition forming liquid droplets (Petzold et al., 2000). There are also some other observations on large spherical particles in the upper troposphere (Sassen et al., 1998; Del Guasta et al., 1998). The sphericity of the particles indicates strongly that they are in fact liquid droplets.

Recent thermodynamic equilibrium model calculations have shown that $\mathrm{HNO}_{3}$ can lower the deliquescence relative humidity (DRH) of ammoniated salts at upper tropospheric conditions (Lin and Tabazadeh, 2002). It was also shown that the most likely ammoniated salt to exist at temperatures near $200 \mathrm{~K}$ is letovicite $\left(\mathrm{NH}_{4}\right)_{3} \mathrm{H}\left(\mathrm{SO}_{4}\right)_{2}$. The DRH of letovicite is normally $87 \%$ at $210 \mathrm{~K}$, but the presence of $2 \mathrm{ppb} \mathrm{HNO}_{3}$ can decrease it down to $43 \%$. The highest observed volume mixing ratios (VMR's) of $\mathrm{HNO}_{3}$ in the upper troposphere are as high as 3 ppb (Laaksonen et al., 1997). High nitric acid VMR's are possible in air masses with continental influence or near flight corridors. Also, sedimentation of nitric acid particles from the stratosphere can cause increased $\mathrm{HNO}_{3}$ concentrations in the UT. In the future, increased air traffic and/or increased $\mathrm{NO}_{\mathrm{x}}$ emissions on the ground may cause high upper tropospheric nitric acid concentrations to occur more frequently, which in turn, may influence the number concentrations of haze mode particles.

The role of ammoniated sulfates in UT aerosol has been discussed in previous studies (e.g. Kärcher and Solomon, 1999; Lin and Tabazadeh, 2002). It is clear, that ammonia neutralizes acidic solutions and so enhances the uptake of $\mathrm{HNO}_{3}$. However, this effect has not been quantified so far for UT aerosols in terms of droplet diameter growth and enhancement of haze mode concentrations. Instead, Lin and Tabazadeh (2002) considered the effect of $\mathrm{HNO}_{3}$ on 

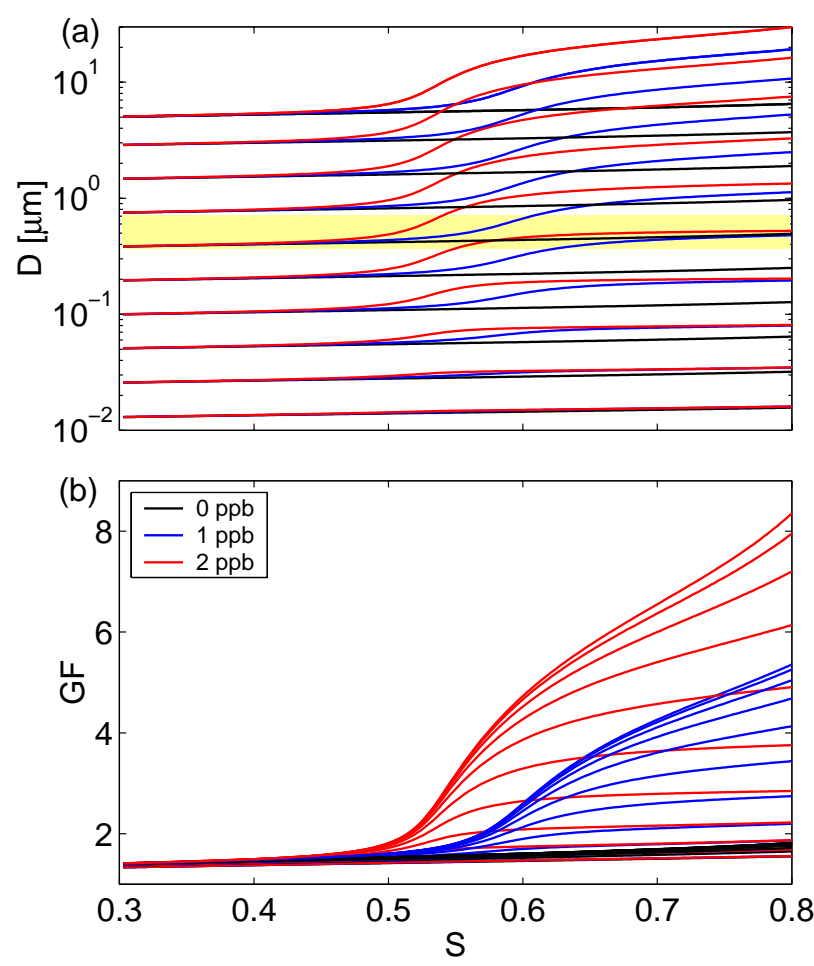

Fig. 1. (a) Growth curves for different size classes for three $\mathrm{HNO}_{3}$ concentrations. Dry aerosol particle distribution is dist A from Table 1. The accumulation mode is illustrated with yellow colour. Particles bigger than that are in the haze mode. (b) Growth factors for different size classes for the same distribution. The highest growth factors are for the biggest particles and vice versa.

the deliquescence $\mathrm{RH}$ of letovicite particles, but not how much $\mathrm{HNO}_{3}$ enhances hygroscopic growth, while Kärcher and Solomon (1999) calculated the effect of $\mathrm{HNO}_{3}$ on sulfuric acid aerosol extinction coefficients as a function of temperature reduced by the local frost point, but did not give quantitative numbers on the effect of $\mathrm{HNO}_{3}$ on ammoniated aerosols.

In the present work, equilibrium equations are used to model nitric acid and water partitioning between gas phase and different aerosol size classes in order to study the influence of $\mathrm{HNO}_{3}$ on upper tropospheric particle growth at different relative humidities. Assuming that sulfuric acid and ammoniated sulfates can be considered completely involatile, the equilibrium requirements are that the saturated vapor pressures of water and nitric acid above the droplet surfaces have to equal the respective partial pressures in the gas. Due to the assumption, the sulfate to ammonium ratio is fixed and independent of RH. Based on the study of Lin and Tabazadeh (2002), we choose letovicite to be the only ammoniated salt studied. For letovicite we calculate the $\mathrm{HNO}_{3}$ dependent DRH. As a case study, equilibrium calculations are compared with the observations of Petzold et al. (2000).
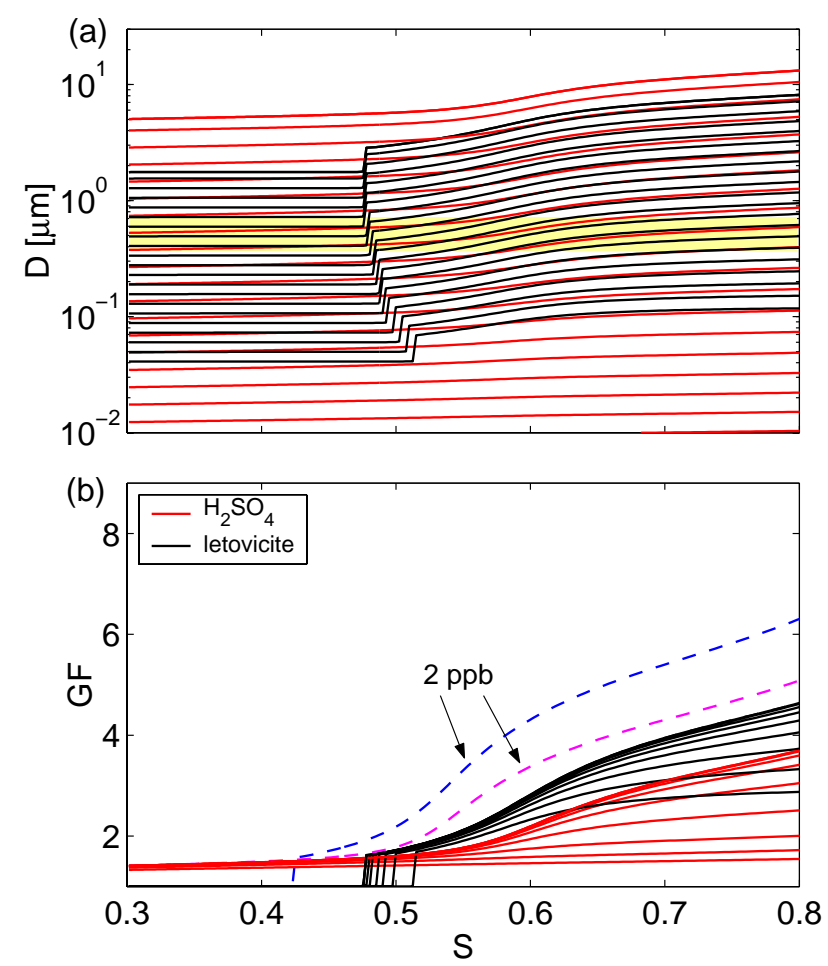

Fig. 2. (a) Growth curves and (b) growth factors for different size classes according to dist B in Table 1. In (a) the accumulation mode is illustrated with yellow colour. For clarity, size-dependent curves are presented only for $1 \mathrm{ppb}$ of $\mathrm{HNO}_{3}$. For $2 \mathrm{ppb}$ of $\mathrm{HNO}_{3}$ only the highest GF's for letovicite (blue) and for $\mathrm{H}_{2} \mathrm{SO}_{4}$ (magenta) are presented

\section{Theory}

The equilibrium saturation ratio $S_{i}$ of vapor $i$ over a multicomponent droplet surface is obtained from

$S_{i}=\frac{p_{i}}{p_{s i}}=f_{i} X_{i} \exp \left(\frac{2 \sigma v_{i}}{R T r}\right)$

where $p_{i}$ is the partial pressure, $p_{s i}$ is the saturation vapor pressure, $X_{i}$ the mole fraction, $f_{i}$ is the activity coefficient, $v_{i}$ is the partial molar volume of species $i, \sigma$ is the surface tension of the solution, $R$ is the gas constant, $T$ is the temperature, and $r$ is the droplet radius.

To describe the equilibrium growth of aerosols we need to write separate equilibrium (Köhler) equations for every condensing vapor. In this study we have equations for water and $\mathrm{HNO}_{3}$. At normal tropospheric conditions, Eq. (1) can be used for water as is, but the amount of $\mathrm{HNO}_{3}$ in the air is small compared to water and we need to take into account the fact that condensation depletes the vapor phase. Using the ideal gas law $(p V=n R T)$ we can write an equilibrium 
Table 1. Parameters for log-normal distributions used in the calculations. In dist A all the modes are composed of sulfuric acid and in dist $\mathrm{B}$ modes 1 and 2 are composed of sulfuric acid and the mode 3 is composed of letovicite with thin sulfuric acid coating.

\begin{tabular}{ccccc}
\hline dist & property & mode 1 & mode 2 & mode 3 \\
\hline A & $N\left[\mathrm{~cm}^{-3}\right]$ & 112.0 & 0.1 & \\
& $D_{p g}[\mu \mathrm{m}]$ & 0.053 & 0.518 & \\
& $\sigma_{g}$ & 1.70 & 1.35 & \\
\hline B & $N\left[\mathrm{~cm}^{-3}\right]$ & 112.0 & 0.1 & 1.25 \\
& $D_{p g}[\mu \mathrm{m}]$ & 0.050 & 0.518 & 0.270 \\
& $\sigma_{g}$ & 1.70 & 1.35 & 1.30 \\
\hline
\end{tabular}

equation that takes account of the mass balance of species $i$ as

$S_{i}=\frac{\left(n_{t i}-n_{d i}\right) C R T}{p_{s i}}=X_{i} f_{i} \exp \left(\frac{2 \sigma v_{i}}{R T r}\right)$,

where $n_{t i}$ is the total amount of moles of substance $i$ in the system per one droplet, $n_{d i}$ is the amount of moles of $i$ in a droplet, and $C$ is the concentration of droplets.

The droplet radius $r$ and the number of moles $n_{d i}$ of condensable substances $i$ (in our case water and nitric acid) can be calculated from Eqs. (2) for a monodisperse droplet population with an iterative method at a given temperature if the total concentrations of $\mathrm{H}_{2} \mathrm{O}$ and $\mathrm{HNO}_{3}$ are known. For the present calculations, the theory is expanded for a discrete particle size distribution including $N$ size classes to obtain sufficient accuracy (see Kokkola et al., 2003, for more details). Equation (2) is thus used to calculate the equilibrium size and the composition of aerosols in each size class as a function of $S_{i}$ in a closed system. In practice, this can be done with the following method. Equation (2) is modified so that $n_{d i}$ and $C$ are replaced with $n_{d i, k}$ and $C_{k}$ where $k$ denotes the number of size class. The number of moles per droplet $n_{t i}$ in size class $b$ under iteration can be expressed as

$n_{t i, b}=\frac{n_{t o t, i}-\sum_{k \neq b} n_{d i, k} C_{k}}{C_{b}}$.

where $n_{t o t, i}$ is the total number of moles of substance $i$ in the system (not per one droplet). By substituting Eq. (3) into Eq. (2) we get a new equation for $\mathrm{HNO}_{3}$ in size class $b$

$\frac{\left(n_{t o t, n}-\sum_{k} n_{d n, k} C_{k}\right) R T}{p_{s n}}=X_{n} f_{n} \exp \left(\frac{2 \sigma v_{n}}{R T r_{b}}\right)$

Now we have two equilibrium equations for every size class, Eq. (1) for water and Eq. (4) for $\mathrm{HNO}_{3}$, These equations are iterated one size class at a time until all size classes are in equilibrium with both condensing vapors. This method is similar to the mass flux iteration method (see e.g. Jacobson, 1999).
Table 2. Parameters for log-normal distributions used in the calculations. Modes 1 and 2 are composed of sulfuric acid and mode 3 is composed of letovicite.

\begin{tabular}{cccccccccc}
\hline dist & \multicolumn{3}{c}{$N\left[\mathrm{~cm}^{-3}\right]$} & \multicolumn{3}{c}{$D_{p g}[\mu \mathrm{m}]$} & \multicolumn{3}{c}{$\sigma_{g}$} \\
\hline & 1 & 2 & 3 & 1 & 2 & 3 & 1 & 2 & 3 \\
\hline $\mathrm{C}_{1}$ & 99 & - & 1 & 0.05 & - & 0.27 & 1.7 & - & 1.3 \\
$\mathrm{C}_{2}$ & 98 & - & 2 & 0.05 & - & 0.27 & 1.7 & - & 1.3 \\
$\mathrm{C}_{3}$ & 97 & - & 3 & 0.05 & - & 0.27 & 1.7 & - & 1.3 \\
$\mathrm{C}_{5}$ & 95 & - & 5 & 0.05 & - & 0.27 & 1.7 & - & 1.3 \\
$\mathrm{C}_{10}$ & 90 & - & 10 & 0.05 & - & 0.27 & 1.7 & - & 1.3 \\
\hline $\mathrm{D}_{0}$ & 100 & 0.1 & 0 & 0.05 & 0.50 & 0.20 & 1.7 & 1.35 & 1.3 \\
$\mathrm{D}_{1}$ & 99 & 0.1 & 1 & 0.05 & 0.50 & 0.20 & 1.7 & 1.35 & 1.3 \\
$\mathrm{D}_{2}$ & 98 & 0.1 & 2 & 0.05 & 0.50 & 0.20 & 1.7 & 1.35 & 1.3 \\
$\mathrm{D}_{3}$ & 97 & 0.1 & 3 & 0.05 & 0.50 & 0.20 & 1.7 & 1.35 & 1.3 \\
$\mathrm{D}_{5}$ & 95 & 0.1 & 5 & 0.05 & 0.50 & 0.20 & 1.7 & 1.35 & 1.3 \\
$\mathrm{D}_{10}$ & 90 & 0.1 & 10 & 0.05 & 0.50 & 0.20 & 1.7 & 1.35 & 1.3 \\
\hline
\end{tabular}

During the iteration we also calculate the saturation ratio of ammonium and sulfate ions with respect to letovicite. If the saturation ratio is over unity, letovicite is in the solid phase. As soon as the saturation ratio drops below unity, deliquescence occurs and letovicite is moved from the solid phase to the liquid phase.

In the present study, the vapor pressures of $\mathrm{H}_{2} \mathrm{O}$ and $\mathrm{HNO}_{3}$ over the solution droplets and the saturation ratio of liquid phase ammonium and sulfate ions with respect to letovicite are calculated using the thermodynamic electrolyte model of Clegg et al. (1998). Data for surface tensions and densities of multicomponent solutions composed of water, nitric acid, sulfuric acid and ammonia are not available, and some approximations are needed. The system is therefore simplified by excluding the effect of ammonia on surface tension and density of the solution, whereby those quantities can be calculated using the expression given by Martin et al. (2000), valid for $\mathrm{H}_{2} \mathrm{SO}_{4} / \mathrm{HNO}_{3} / \mathrm{H}_{2} \mathrm{O}$-solutions.

\section{Growth factors}

In the following calculations concerning upper troposphere we assume (unless otherwise stated) that the total pressure $p=200$ mbar and the initial temperature and water vapor saturation ratio are $T_{0}=206 \mathrm{~K}$ and $S_{0}=0.3$. In conformity with Petzold et al. (2000), we define the haze and the accumulation mode to consist of droplets larger than $0.72 \mu \mathrm{m}$ in diameter and droplets with diameter between $0.37 \mu \mathrm{m}$ and 0.72 $\mu \mathrm{m}$, respectively. Both $\mathrm{H}_{2} \mathrm{SO}_{4}$ and $\mathrm{NH}_{3}$ are assumed to remain in the droplets during the equilibrium growth in accordance with the original distribution. The size distributions are presented in Table 1. Distribution A is similar to those reported in the article of Petzold et al. (2000). The dry 


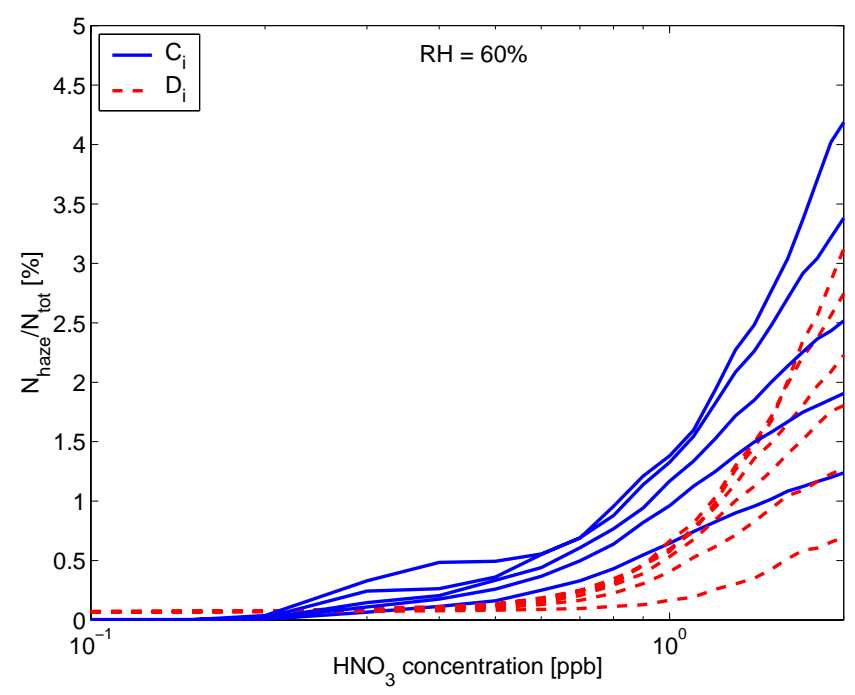

Fig. 3. Number concentration ratio $N_{\text {haze }} / N_{\text {tot }}$ as a function of $\mathrm{HNO}_{3}$ concentration at $60 \% \mathrm{RH}$ for size distributions presented in Table 2. The lowermost curves of $\mathrm{C}_{i}$ and $\mathrm{D}_{i}$ correspond to distributions $C_{1}$ and $D_{0}$ in Table 2 and the uppermost correspond to $C_{10}$ and $\mathrm{D}_{10}$, respectively.

radius is obtained by dividing values given at $S=0.38$ by a factor of 1.4, which is estimated to be the growth factor of $\mathrm{H}_{2} \mathrm{SO}_{4} / \mathrm{H}_{2} \mathrm{O}$-solution droplets at that saturation ratio.

With these initial values, homogeneous freezing would take place at $S \gtrsim 0.78(T \sim 199 \mathrm{~K})$ depending on droplet size and timescale of the process (Koop et al., 2000).

\section{$3.1 \quad \mathrm{H}_{2} \mathrm{SO}_{4} / \mathrm{HNO}_{3} / \mathrm{H}_{2} \mathrm{O}$}

In Fig. 1a we present growth curves for different size classes for distribution A at 3 different $\mathrm{HNO}_{3}$ VMR's as a function of saturation ratio. In the calculations the number of size classes was higher but for clarity only 10 are presented in the figure. In the Fig. 1a the accumulation mode is presented with yellow colour. The growth due to $\mathrm{HNO}_{3}$ uptake is clear.

Figure $1 \mathrm{~b}$ presents growth factors (=droplet diameter divided by the dry particle diameter) for the same distribution and reveals that the equilibrium growth factors are not size-independent. Because the Kelvin effect tends to increase the saturated vapor pressures, the concentrations of $\mathrm{H}_{2} \mathrm{O}$ and $\mathrm{HNO}_{3}$ have to decrease with decreasing droplet diameter in order to ensure equilibrium for all sizes. Previously, Carslaw et al. (1997) have noted that the equilibrium composition of stratospheric ternary droplets are size dependent (however, they did not calculate the effect on growth factors).

\section{$3.2 \quad\left(\mathbf{N H}_{4}\right)_{3} \mathbf{H}\left(\mathbf{S O}_{4}\right)_{2}$}

In Fig. 2, growth curves are presented for distribution B (see Table 1) containing an additional mode of letovicite. Figure 2 shows the growth of the letovicite mode as a function

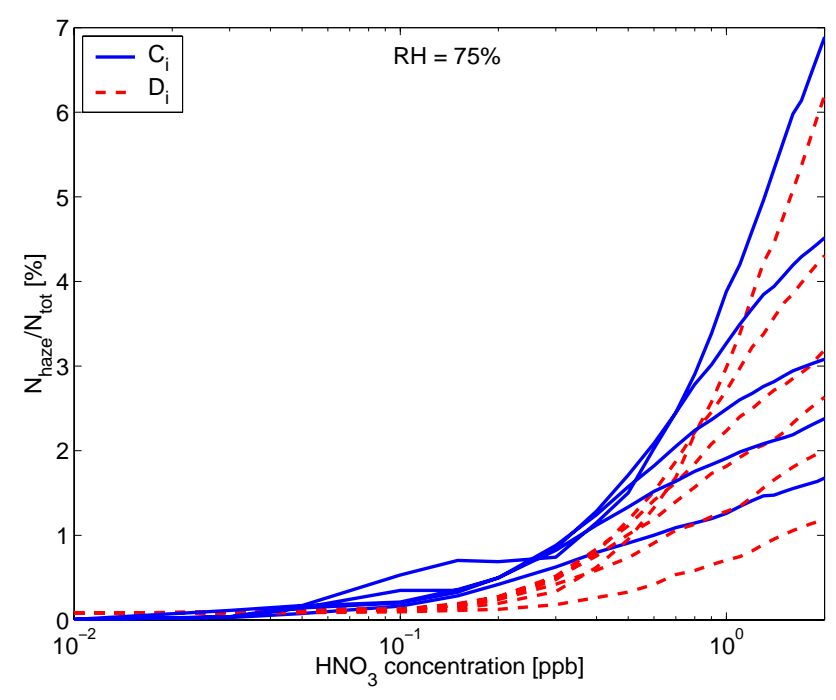

Fig. 4. Like Fig. 3 but $\mathrm{RH}$ is now $75 \%$.

of $S$ (black lines). It can be seen that with $1 \mathrm{ppb}$ of $\mathrm{HNO}_{3}$ the DRH of letovicite is at $47.8 \%$. At that point, the particles instantly take up $\mathrm{HNO}_{3}$ and $\mathrm{H}_{2} \mathrm{O}$ to maintain equilibrium. The GF due to pure deliquescence is approximately 1.15 . The rest of the growth is caused by simultaneous uptake of $\mathrm{HNO}_{3}$ and $\mathrm{H}_{2} \mathrm{O}$. The total GF at the DRH is 1.65. An assumption of different ammonium to sulfate ratio than that of letovicite would change the deliquescence behaviour of particles (see Lin and Tabazadeh, 2002) and thus change the GF at the DRH. However, based on Lin and Tabazadeh (2002), letovicite will be formed in the solid phase also for nonstochiometric ammonium to sulfate ratios and so there will be at least partial deliquescence at the DRH of letovicite.

It can also be seen that the DRH is size dependent. The smallest particles persist in the solid state to higher RH than do the bigger ones. The first particles to become deliquescent are those with the highest $\mathrm{HNO}_{3}$ content in the aqueous coating. Because of the Kelvin effect, the highest equilibrium concentration occurs on the biggest particles. Smaller particles with a lower $\mathrm{HNO}_{3}$ concentration in the liquid layer experience deliquescence at a higher $\mathrm{RH}$.

From Figs. 1 and 2 we can see that the highest GF's for letovicite are indeed lower than for $\mathrm{H}_{2} \mathrm{SO}_{4}$ when the letovicite is absent. There are two reasons for that, the total volume of the distribution $\mathrm{B}$ is bigger than the volume of the distribution $\mathrm{A}$ and the GF of $\left(\mathrm{NH}_{4}\right)_{3} \mathrm{H}\left(\mathrm{SO}_{4}\right)_{2}-\mathrm{H}_{2} \mathrm{O}$ droplets is smaller that the GF of $\mathrm{H}_{2} \mathrm{SO}_{4}-\mathrm{H}_{2} \mathrm{O}$ droplets. However, the equilibrium growth of letovicite particles is not as sizedependent as is the growth of $\mathrm{H}_{2} \mathrm{SO}_{4}$-particles and so the presence of letovicite particles increases the number of haze mode droplets. 

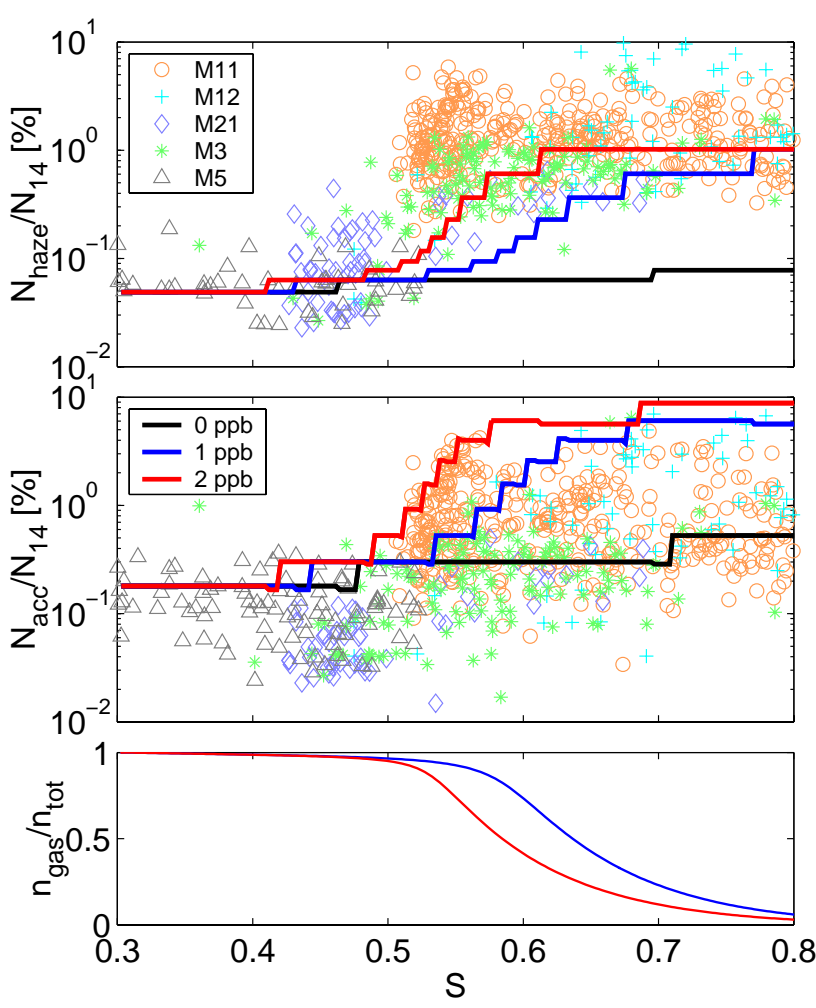

Fig. 5. Comparison to observations of Petzold et al. (2000) for distribution A (pure sulfuric acid droplets) at three different $\mathrm{HNO}_{3}$ VMR's. Different symbols representing the observations (M11, M12, M21, M3, M5) refer to different POLSTAR II flights. For more information about measurements see Petzold et al. (2000). $N_{\text {haze }} / N_{14}$ is the ratio of particles with diameter between $0.72 \mu \mathrm{m}$ and $10 \mu \mathrm{m}$ to particles with diameter bigger than $0.014 \mu \mathrm{m}$. $N_{a c c} / N_{14}$ is the ratio of particles with diameter between $0.37 \mu \mathrm{m}$ and $0.72 \mu \mathrm{m}$ to particles with diameter bigger than $0.014 \mu \mathrm{m}$. $n_{\text {gas }} / n_{\text {tot }}$ is the ratio of gas phase $\mathrm{HNO}_{3}$ to the total $\mathrm{HNO}_{3}$ concentration.

\section{Effect of increased $\mathrm{HNO}_{3}$ and letovicite concentra- tions on the number of haze particles}

From the examination above it is clear that both increased $\mathrm{HNO}_{3}$, and increased letovicite concentrations lead to increased numbers of haze mode particles. This effect is further demonstrated in Figs. 3 and 4 presenting the ratio of haze mode particles to all particles as a function of $\mathrm{HNO}_{3}$ concentration for 11 different aerosol particle distributions (Table 2) containing different amounts of sulfuric acid and letovicite. Figure 3 shows that at $60 \%$ relative humidity, nitric acid concentrations below about $0.2 \mathrm{ppb}$ have little effect on the haze mode. However, above $0.2 \mathrm{ppb}$, enough of $\mathrm{HNO}_{3}$ is absorbed by the droplets to cause a substantial increase in $N_{\text {haze }}$. At $75 \% \mathrm{RH}$, only $0.1 \mathrm{ppb}$ of nitric acid is needed for a similar effect. This is due to the lowered $\mathrm{HNO}_{3}$ vapour pressure over solution droplets and $\mathrm{HNO}_{3}$ dependent
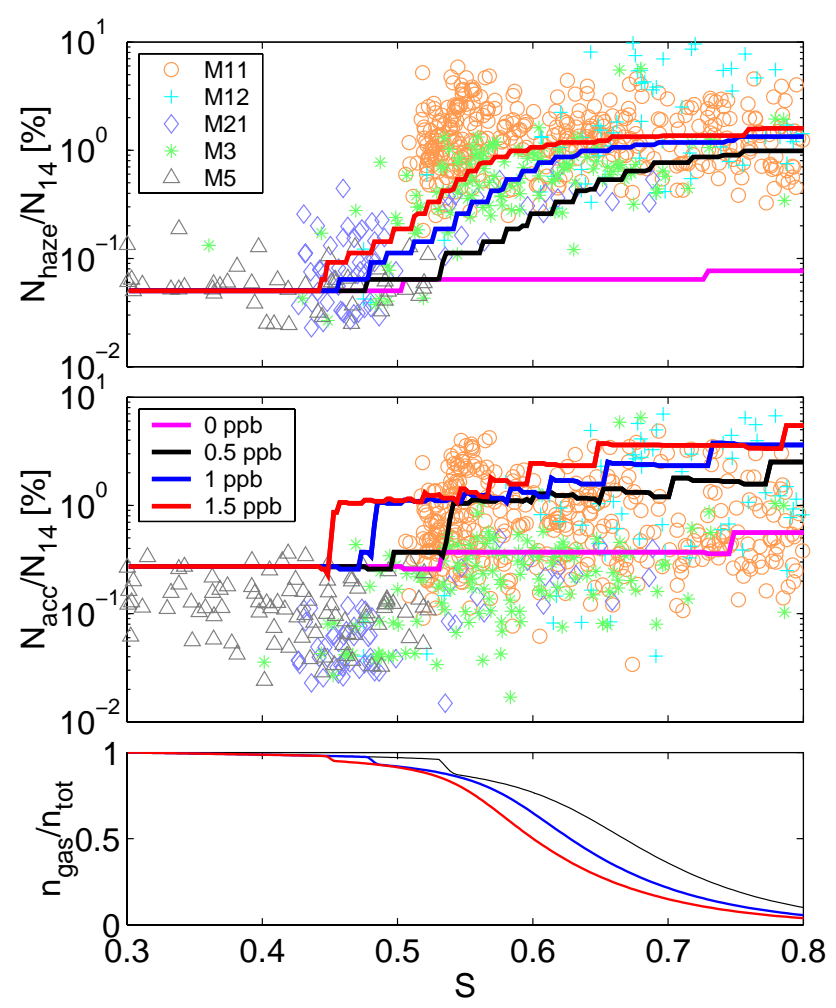

Fig. 6. Comparison to observations of Petzold et al. (2000) for distribution $\mathrm{B}$ containing letovocite with four different $\mathrm{HNO}_{3}$ concentrations. Axes are same as in the Fig. 5.

deliquescence of letovicite. With increasing $\mathrm{HNO}_{3}$ concentrations, the fraction of haze mode particles to all particles can increase to more than 5\% depending on the amount and size of letovicite particles present.

Even without letovicite, the haze mode concentration can increase to more than $1 \mathrm{~cm}^{-3}$, but the amount of $\mathrm{HNO}_{3}$ needed is higher than in the presence of letovicite particles. Altogether, the variation in the haze mode concentrations for the different size distributions shown in Table 2 is close to an order of magnitude at both $60 \%$ and $75 \%$ relative humidities. Nitric acid causes a substantial enhancement of haze mode particles already when the aerosol distribution is composed of sulfuric acid alone, however, the presence of letovicite magnifies the effect greatly.

\section{A case study}

Petzold et al. (2000) observed pronounced increases of upper tropospheric haze mode particles at relative humidities above $50 \%$. Here, we compare our calculations to the observation in order to examine whether nitric acid may have contributed to the haze mode concentrations. To be able to carry out the comparison, we define two modes with size limits $0.37 \mu \mathrm{m}<D<0.72 \mu \mathrm{m}$ (accumulation 


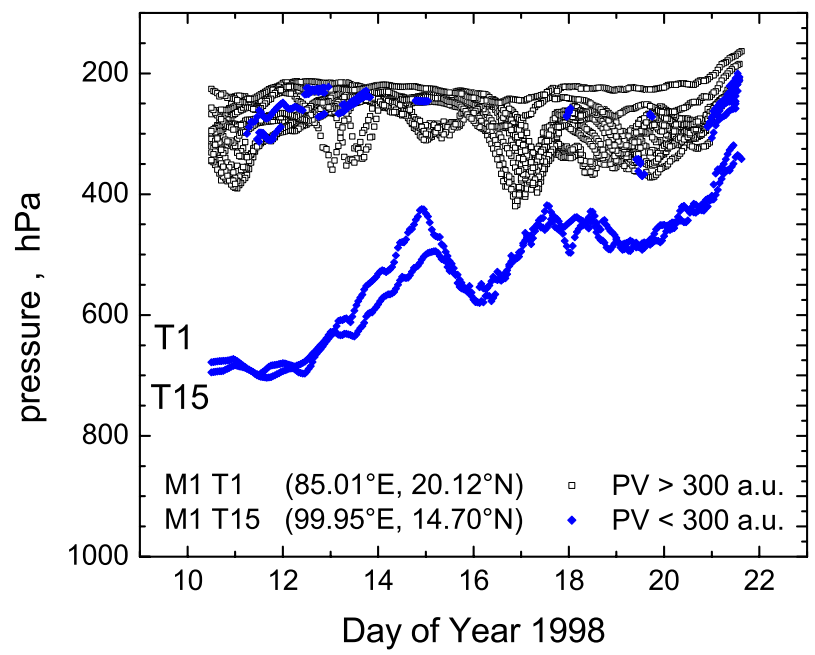

Fig. 7. History of air parcels encountered during mission flight 1 on 21 January 1998 given as pressure altitude vs. time. Blue symbols indicate air parcels of tropospheric origin (scaled potential vorticity $<300$ ), while black symbols indicate air masses of stratospheric origin (scaled potential vorticity $>300$ ). Starting points of tropospheric trajectories are labelled as T1 and T15

mode) and $0.72 \mu \mathrm{m}<D<10 \mu \mathrm{m}$ (haze mode). Due to the measurement setup, the modes defined by Petzold et al. (2000) were $0.37 \mu \mathrm{m}<D<0.69$ and $0.75 \mu \mathrm{m}<D<10 \mu \mathrm{m}$, but this difference should not influence our analysis too much. Figure 5 shows the concentration ratios $N_{a c c} / N_{14}$ and $N_{\text {haze }} / N_{14}$, where $N_{14}$ is the concentration of all particles with $D>0.014 \mu \mathrm{m}$, as a function of the saturation ratio of water vapor at different nitric acid VMR's when the aerosol is composed of sulfuric acid and water (distribution A of Table 1). Also the partitioning of nitric acid between the gas and the liquid phases is shown. The data-points in Fig. 5 are the observations of Petzold et al. (2000).

The observed increase in the number of accumulation mode particles is consistent with the modeled increase caused by uptake of nitric acid on liquid $\mathrm{H}_{2} \mathrm{SO}_{4} / \mathrm{H}_{2} \mathrm{O}$. It seems that an average of less than $1 \mathrm{ppb}$ of $\mathrm{HNO}_{3}$ is needed to explain the behaviour of the accumulation mode particle concentration, and VMR's above 2 ppb would lead to an overestimation of the increase in $N_{a c c} / N_{14}$. A small increase in number of the accumulation mode particles can be seen even without $\mathrm{HNO}_{3}$ but not nearly enough to explain the observations.

The increase in the number of haze mode particles is more problematic. It clearly cannot be explained without the influence of $\mathrm{HNO}_{3}$. However, even nitric acid is not able to explain all of the observations; with haze mode particles, more than $2 \mathrm{ppb}$ of $\mathrm{HNO}_{3}$ would be needed to explain a large part of the increase in the haze mode. By adjusting the initial size distribution, the model results could be made to match the observations somewhat better, i.e. a larger increase in haze mode would be seen at a given nitric acid VMR. However, this would inevitably cause an increase also in the accumulation mode concentration, spoiling the agreement obtained with the size distribution A of Table 1, which is very similar to the distribution measured at $S=0.53$ (see Table 4 in Petzold et al., 2000). Only the number densities of different modes are slightly adjusted to get better agreement with observation data at low saturation ratios.

Petzold et al. (2000) proposed, that their observations could be explained with particles undergoing deliquescence. In Fig. 6 we compare our results for distribution B (see Table 1) containing letovicite to their observations. We have ammonia only in mode 3 because it is likely that the UT air considered here contains an external mixture of aerosol particles: sulfuric acid aerosols formed in situ in the UT, and letovicite containing particles originating from mixing of air that has had contact with the surface. Moreover, like already stated in the Petzold et al. (2000) paper, the accumulation mode particles behave as if they are $\mathrm{H}_{2} \mathrm{SO}_{4}-\mathrm{H}_{2} \mathrm{O}$ droplets. The increase in haze mode particle concentration fits the measurements better than with distribution A. This is because with proper selection of $\mathrm{HNO}_{3}$ concentration the DRH of letovicite can be adjusted to occur at $S=0.5$. The amount of $\mathrm{HNO}_{3}$ needed is close to $1 \mathrm{ppb}$. Without letovicite, $2 \mathrm{ppb}$ of $\mathrm{HNO}_{3}$ is needed to get as good agreement for the haze mode. After deliquescence, more $\mathrm{HNO}_{3}$ is partitioned in droplets containing letovicite than in $\mathrm{H}_{2} \mathrm{SO}_{4} / \mathrm{H}_{2} \mathrm{O}$ droplets. That can be seen by comparing the growth of $\mathrm{H}_{2} \mathrm{SO}_{4}$ droplets in Figs. 1 and 2.

It can be seen that our equilibrium model predicts too high accumulation mode concentration if we adjust the haze mode concentration behavior within observations. In order to make the letovicite particles to increase the haze mode enough, the letovicite distribution is such that the accumulation mode of distribution B has more particles than that of distribution A already at $S=0.3$ (see Table 1 and Figs. 2 and 4). Growth of the letovicite particles due to the deliquescence and nitric acid uptake from sizes below the accumulation mode is not strong enough to bring them directly to the haze mode as deliquescence takes place. Growth factors over 2 (up to 3) would be needed for particles undergoing deliquescence to explain the observations, whereas for letovicite the growth factor (including the uptake of $\mathrm{HNO}_{3}$ ) is only 1.65 (see Fig. 2). The GF could be different if the ammonium to sulfate ratio was different from that of letovicite and thus the assumption of a fixed composition can produce some uncertainty into our analysis.

However, discussing the agreement between observations and modeling results should consider the random-type nature of the observations as presented by Petzold et al. (2000). The data were obtained by compiling all observations in the upper free troposphere during the POLSTAR 2 experiment. In the case of high ozone concentrations $>220 \mathrm{ppb}$ and simultaneously observed low relative humidities $\leq 20 \%$ data were identified as from the lower stratosphere and were excluded. 
In total, $40 \%$ of the data originate from drier air masses with $S \leq 0.45,15 \%$ originate from air masses close to ice saturation with $S \sim 0.50$, and the remaining $45 \%$ originate from humid air masses above ice saturation with $S \geq 0.55$. Hence, the air masses close to ice saturation are not equally represented compared to more dry and more humid air masses, respectively. Additionally, no Lagrangian flights with the focus on particle formation and growth were performed during POLSTAR 2. The gap between the accumulation mode and the haze mode which occurs in the model results compared to the observations, is likely to be explainable by the missing information for air masses around ice saturation. The size distributions $\mathrm{A}$ and $\mathrm{B}$ used for the modeling studies are both likely to occur compared to the observed average number density of $\sim 1 \mathrm{~cm}^{-3}$ for particles in the size range $0.37 \mu \mathrm{m}<D<0.72 \mu \mathrm{m}$. Hence, the observations do not allow for an unambiguous preference for one of the selected size distributions.

In order to examine the likehood that enhanced $\mathrm{HNO}_{3}$ concentrations and ammoniated aerosols were actually present in the air masses encountered during the POLSTAR 2 flights, trajectory analysis was done. Measured data were sorted according to the related ozone level for separating tropospheric and stratospheric air masses. To obtain a similar separation for trajectory data, the potential vorticity scaled by atmospheric pressure was used. The analysed data suggest a clear separation of mainly tropospheric from mainly stratospheric air at a value of 300-400 scaled PV units. For all mission flights when haze mode events were observed, the trajectories indicate a lifting of tropospheric air parcels during the past 10 to 12 days prior to the measurement. The origin of these tropospheric air masses varies between 14 and $37 \mathrm{deg}$. $\mathrm{N}$ and 85 to $118^{\circ} \mathrm{E}$, i.e. from the Eurasian continent. Figure 7 shows an example for mission flight 1. Blue symbols indicate $\mathrm{PV}<300$ a.u. while black symbols indicate $\mathrm{PV}>300$ a.u.. Summarising, the trajectory data analysis supports the assumption that air masses close to the polar tropopause can be influenced by boundary layer air masses from lower latitudes and can thus carry chemical species of continental origin.

As reported by Krämer et al. (2003), the VMR of $\mathrm{HNO}_{3}$ during the POLSTAR 2 experiment was on the order of $0.5 \mathrm{ppb}$. During the flight M3 of POLSTAR 2, the VMR of $\mathrm{HNO}_{3}$ varied between 0.2 and $0.9 \mathrm{ppb}$ (green stars in our Figs. 5 and 6, see fig 1 of Krämer et al. (2003)). The model results for the accumulation mode are in good agreement with the $\mathrm{HNO}_{3}$ observations. Without overrating the observations, they also support the model results which indicate a considerable growth of an upper tropospheric haze mode in the presence of sufficient $\mathrm{HNO}_{3}$.

\section{Conclusions}

We have shown that uptake of nitric acid by upper tropospheric aerosols causes notable increases in haze mode particle concentrations at relative humidities above $50 \%$. At a relative humidity of $75 \%$, a few tenths of a ppb of $\mathrm{HNO}_{3}$ is enough to have an effect when the aerosol is composed of pure sulfuric acid. The presence of letovicite can substantially enhance the nitric acid effect, decreasing the threshold to about $0.1 \mathrm{ppb}$, and causing a severalfold increase in the haze mode concentrations at a given $\mathrm{HNO}_{3}$ concentration. Our equilibrium calculations indicate that uptake of nitric acid by sulfuric acid aerosol may at least partially explain the observed increases of upper tropospheric haze- and accumulation mode particles at relative humidities above $50 \%$. A letovicite mode improved the agreement between calculations and observations somewhat. The required $\mathrm{HNO}_{3}$ levels were on the order of 1-2 ppb with sulfuric acid particles and 0.5-1 ppb when the letovicite mode was present.

Acknowledgements. We thank S. L. Clegg for providing us with a computer code of the AIM thermodynamic model. The trajectory analysis within POLSTAR 2 was conducted by Raimond Alfier from Meteorologisches Institut der Freien Universitaet Berlin. This study was supported by the Academy of Finland.

Edited by: S. Martin

\section{References}

Carslaw, K. S., Peter, T., and Clegg, S. L.: Modeling the composition of liquid stratospheric aerosols, Rev. Geophys., 35, 125-154, 1997.

Clegg, S. L., Brimblecombe, P., and Wexler, A. S.: A thermodynamic model of the system at tropospheric temperatures, J. Phys. Chem. A, 102, 2137-2154, 1998.

Del Guasta, M., Morandi, M., Stefanutti, L., Balestri, S., Kyrö, E., Rummukainen, M., Kivi, R., Rizi, V., Stein, B., Wedekind, C., Mielke, B., Matthey, R., Mitev, V., and Douard, M.: Lidar observations of spherical particles in a $-65^{\circ}$ cold cirrus observed above Sodankylä (Finland) during S.E.S.A.M.E, J. Aerosol Sci., 29, 357-374, 1998.

Jacobson, M. Z.: Fundamentals of Atmospheric Modeling, Cam. Univ. Press, 1999.

Kärcher, B. and Solomon, S.: On the composition and optical extinction of particles in the tropopause region, J. Geophys. Res. 104, 27 441-27 459, 1999.

Kokkola, H., Romakkaniemi S., and Laaksonen A.: Köhler theory for a polydisperse droplet population in the presence of a soluble trace gas, and an application to stratospheric STS droplet growth, Atmos. Chem. Phys., 3, 2139-2146, 2003.

Koop, T., Luo, B., Tsias, A., and Peter, T.: Water activity as the determinant for homogenous ice nucleation in aqueous solutions, Nature, 406, 611-614, 2000.

Krämer, M., Beuermann, J., Schiller, C., Grimm, F., Arnold F.,Peter, Th., Meilinger, S., Meier, A., Hendricks,J., Petzold, A., and Schlager, H.: Nitric acid partitioning in cirrus clouds: a syn- 
opsis based on field, laboratory and model studies, Atmos. Chem. Phys. Discuss., 3, 413-443, 2003.

Laaksonen, A., Hienola, J., Kulmala, M., and Arnold, F.: Supercooled cirrus cloud formation modified by nitric acid pollution of the upper troposphere, Geophys. Res. Lett., 24, 3009-3012, 1997.

Lin, J. S. and Tabazadeh, A.: The effect of nitric acid uptake on the deliquescence end efflorescence of binary ammoniated salts in the upper troposphere, Geophys. Res. Lett., 29, 126-1-4, 2002.

Martin, E., George, C., and Mirabel, P.: Densities and surface tensions $\mathrm{H}_{2} \mathrm{SO}_{4} / \mathrm{HNO}_{3} / \mathrm{H}_{2} \mathrm{O}$ solutions, Geophys. Res. Lett., 27, 197-200, 2000.

Murphy D. M., Thomson, D. S., and Mahoney, M. J.: In situ measurements of organics, meteoritic material, mercury, and other elements in aerosols at 5 to $19 \mathrm{~km}$, Science, 282, 1664-1669, 1998.
Petzold, A., C. Hoell, C., Kärcher, B., Beuermann, J., Schiller, C., Ziereis, H., and Schlager, H.: In situ observations of aerosol properties above ice saturation in the polar tropopause region, J. Geophys. Res., 105, 29 387-29395, 2000.

Sassen K., Arnott, W. P., Barnett, J. M.,and Aulenbach, S.: Can cirrus clouds produce glories, Appl. Opt., 37, 1427-1433, 1998.

Sheridan, P. J., Brock, C. A., and Wilson, J. C.: Aerosol particles in the upper troposphere and lower stratosphere: elemental composition and morphology of individual particles in northern midlatitudes, Geophys. Res. Lett., 21, 2587-2590, 1994.

Tabazadeh, A., Turco, R. P., and Jacobson, M. Z.: A model for studying the composition and chemical effects of stratospheric aerosols, J. Geophys. Res., 99, 12 897-12 914, 1994.

Xu, L., Okada, K., Iwasaka, Y., Hara, K., Okuhara, Y., Tsutsumi, Y., and Shi, G.: The composition of individual aerosol particle in the troposphere and stratosphere over Xianghe $\left(39.45^{\circ} \mathrm{N}, 117.0^{\circ} \mathrm{E}\right)$, Atmos. Environ., 35, 3145-3153, 2001. 